STUDI

FRANCESI

\section{Studi Francesi}

Rivista quadrimestrale fondata da Franco Simone

165 (LV | III) | 2011

LA RAPPRESENTAZIONE DELLA MADRE NELLA

LETTERATURA FRANCESE DEL NOVECENTO a cura di Dario Cecchetti e Michele Mastroianni

\title{
Barbara Bohac, Baudelaire et Liszt: le génie de la rhapsodie
}

\section{Maria Emanuela Raffi}

\section{(2) OpenEdition \\ Journals}

Edizione digitale

URL: http://journals.openedition.org/studifrancesi/5087

DOI: 10.4000/studifrancesi.5087

ISSN: 2421-5856

Editore

Rosenberg \& Sellier

Edizione cartacea

Data di pubblicazione: 1 décembre 2011

Paginazione: 665

ISSN: 0039-2944

Notizia bibliografica digitale

Maria Emanuela Raffi, «Barbara Bohac, Baudelaire et Liszt: le génie de la rhapsodie», Studi Francesi

[Online], 165 (LV | III) | 2011, online dal 30 novembre 2015, consultato il 09 janvier 2021. URL: http:// journals.openedition.org/studifrancesi/5087 ; DOI: https://doi.org/10.4000/studifrancesi.5087

Questo documento è stato generato automaticamente il 9 janvier 2021.

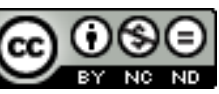

Studi Francesi è distribuita con Licenza Creative Commons Attribuzione - Non commerciale - Non opere derivate 4.0 Internazionale. 


\title{
Barbara Bohac, Baudelaire et Liszt: le génie de la rhapsodie
}

\author{
Maria Emanuela Raffi
}

\section{NOTIZIA}

BARBARA BOHAC, Baudelaire et Liszt: le génie de la rhapsodie, «Romantisme» n. 151, 2011,

pp. 87-99.

1 I rapporti fra Baudelaire e Liszt, iniziati nel 1861 con la protettiva amicizia del musicista nei confronti del poeta e continuati con la dedica a Franz Liszt del poema in prosa «Le Thyrse», appaiono nello studio di Barbara Bohac più complessi e profondi. Un ruolo fondamentale gioca infatti il volume di Liszt Des Bohémiens et de leur Musique en Hongrie del 1859, di cui il musicista ungherese fa omaggio a Baudelaire e che l'autore delle Fleurs du mal riprende in parte nei suoi poèmes en prose, non solo nel «Thyrse», ma soprattutto in «Les Vocations», mentre risonanze baudelairiane appaiono nelle affermazioni di Liszt sui bohémiens. La Bohac conclude lo studio con l'ipotesi di un parallelismo strutturante e tutt'altro che accidentale: «le libre jeu de la fantaisie, l'art de l'improvisation» che per Baudelaire rappresentano la trasposizione operata da Liszt della musica bohémienne, l'arte cioè della rapsodia, trovano un puntuale riscontro nella realizzazione dei poèmes en prose baudelairiani, «rhapsodie de la civilisation moderne». 